\title{
DIAGNÓSTICO DE VULNERABILIDADE AMBIENTAL A PARTIR DE FERRAMENTAS DE GEOPROCESSAMENTO
}

\section{ENVIRONMENTAL VULNERABILITY FROM GEOPROCESSING TOOLS}

\author{
Apresentação: Pôster
}

Samanta Francisca Felix dos Santos ${ }^{1}$; Larissa Nicácio Pessoa ${ }^{2}$; Zenaide Gomes da Silva ${ }^{3}$; Erickson Melo de Albuquerque ${ }^{4}$; Artur Moisés Gonçalves Lourenço ${ }^{5}$

\section{DOI: https://doi.org/10.31692/2526-7701.IIICOINTERPDVAGRO.2018.00428}

\section{Introdução}

No século XX, os centros urbanos passaram a representar locais de desenvolvimento e de crescimento populacionais, o processo de crescimento das cidades acelerou por duas razões a necessidade de mão-de-obra com menor preço e a migração das zonas rurais para os centros urbanos em busca de condições melhores, seja o acesso aos hospitais e a facilidade em encontrar alimentos industrializados. Ocasionando um processo de êxodo rural, transformando as cidades em grandes aglomerados sem planejamento algum para os receber, criando as grandes periferias (SOUZA, 2013).

Ainda segundo o autor Sousa (2013), esse crescimento trouxe muitos benefícios, mas ocasionou uma série de fatores negativos, como a ocupação indiscriminada do território, com o auxílio de tecnologias pouco adaptadas, não levando em consideração a degradação causada ao meio ambiente. A partir disso, surge a necessidade de uma ferramenta, que possa ser utilizada para que o uso do solo e ocupação pudessem ser feitos de maneira racional.

O zoneamento ambiental é um instrumento amplamente utilizado nos planos diretores, através do qual a cidade é dividida em áreas sobre as quais incidem diretrizes diferenciadas para o uso e a ocupação do solo, especialmente os índices urbanísticos (PAIXÃO; AIALA, 2013).

\footnotetext{
${ }^{1}$ Tecnologia em Gestão Ambiental, IFPB, samantafelix22@gmail.com

${ }^{2}$ Tecnologia em Gestão Ambiental, IFPB, larissanicaciodasilva@gmail.com

${ }^{3}$ Tecnologia em Gestão Ambiental, IFPB, zenaidegomesif@gmail.com

${ }^{4}$ Mestre, IFPB, erickson.melo@academico.ifpb.edu.br

${ }^{5}$ Mestre, IFPB, artur.moises@academico.ifpb.edu.br
} 
Considerando-se que as características ambientais devem ser avaliadas de forma associada na elaboração de um zoneamento, organizou-se uma base de imagens de satélites para serem trabalhadas em uma ferramenta de geoprocessamento, com o auxílio das informações disponibilizadas a partir do censo demográfico de 2010. Essas informações foram utilizadas para construir um conjunto de mapas temáticos com o objetivo de caracterizar o município de acordo com o saneamento básico, a arborização, pavimentação e os equipamentos urbanos que existem no município.

\section{Fundamentação Teórica}

O zoneamento ambiental foi previsto como um dos instrumentos da PNMA (Política Nacional do Meio Ambiente) - Lei 6.938/81, tendo por objetivo "a preservação, melhoria e recuperação da qualidade ambiental propícia à vida, visando assegurar, no País, condições ao desenvolvimento socioeconômico, aos interesses da segurança nacional e à proteção da dignidade da vida humana" (BRASIL, 1981). Segundo Santos e Ranieri (2013), a PNMA institui o Zoneamento Ambiental, a fim de que este, articulado aos outros instrumentos por ela propostos, contribua na preservação, melhoria e recuperação da qualidade ambiental, bem como no desenvolvimento socioeconômico, na segurança nacional e na proteção à dignidade da vida humana.

O mapeamento de vulnerabilidade é importante na avaliação ambiental e na análise de tendências futuras, além de permitir um planejamento adequado do desenvolvimento socioeconômico da área, onde medidas poderão ser apontadas para minimizar possíveis impactos causados ao meio ambiente pelas atividades antrópicas desenvolvidas (ARAÚJO; AMARO e VITAL, 2003). Mapas de Vulnerabilidade Ambiental são ferramentas de alta importância, pois nos fornecem informações para o planejamento ambiental de uma região, bem como sua avaliação em caso de danos com desastres ecológicos (MMA, 2002).

\section{Metodologia}

As análise de zoneamento urbano do presente trabalho foram realizadas na cidade de Princesa Isabel que se localiza na microrregião da Serra do Teixeira, no Estado da Paraíba, possuindo uma área territorial de $367,975 \mathrm{~km}$, população de 22.995 , densidade demográfica de 57,84 (habitante/ $\mathrm{km}^{2}$ ), IDH de 0,606 e bioma Caatinga, de acordo o Instituto Brasileiro de Geografia e Estatística (IBGE, 2010). 
A composição dos mapas foi possível, a partir dos dados obtidos no portal do IBGE (Instituto Brasileiro de Geografia e Estatística), dados sobre o saneamento da cidade, como: saneamento básico, a arborização e pavimentação; referentes ao último censo demográfico de 2010, nos mapas foram utilizados os limites dos setores censitários disponibilizados pelo IBGE, sendo que não foram utilizado as delimitações pois o município não possui malha dos bairros, com isso foram considerados as características ambientais, que foram organizadas com base de imagens satélite sendo trabalhada no programa Quantum GIS 2.18 que é um programa de Sistema de Informação Geográfica com código aberto e licenciado sob a Licença Pública Geral GNU.

\section{Resultados e Discussões}

A partir dos dados adquiridos no censo demográfico no IBGE, foram elaborados mapas que mostraram as características do município de acordo com o saneamento básico, a arborização, pavimentação e os equipamentos urbanos que existe no mesmo.

Figuras1, 2 ,3 ,4, 5- Mapas temáticos referente ao saneamento básico da cidade.

1)

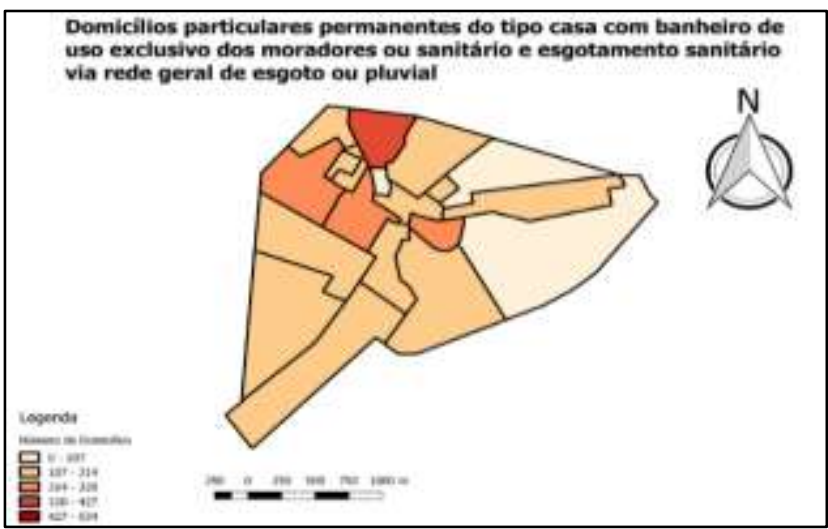

3)

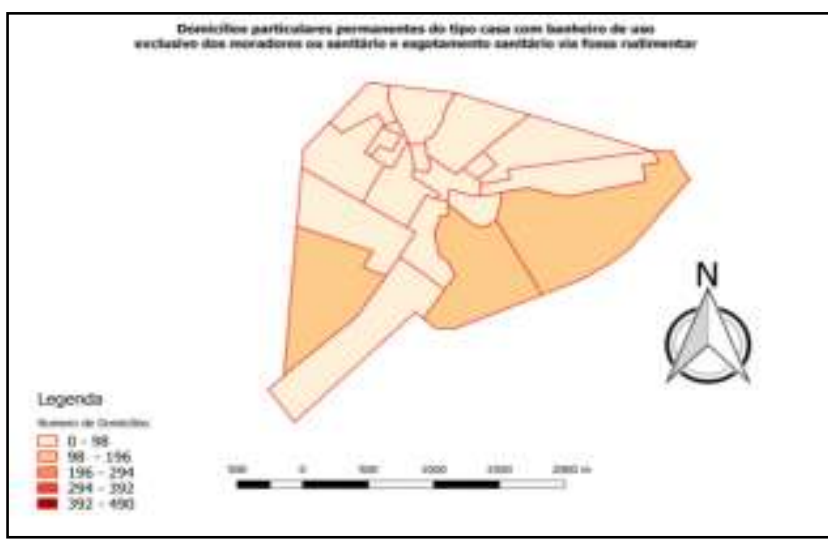

2)

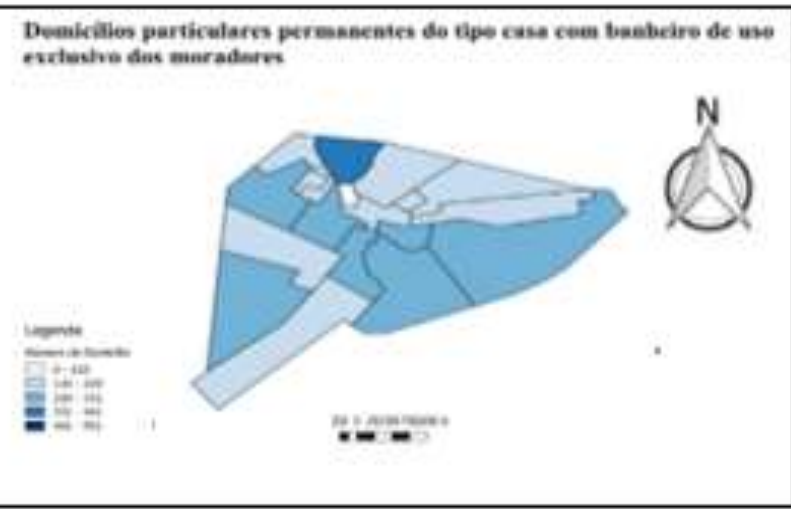

4)

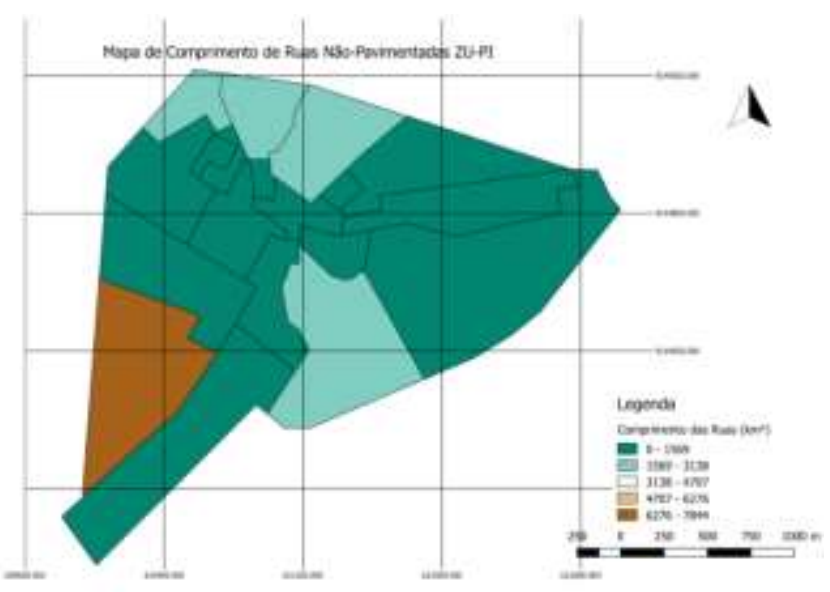




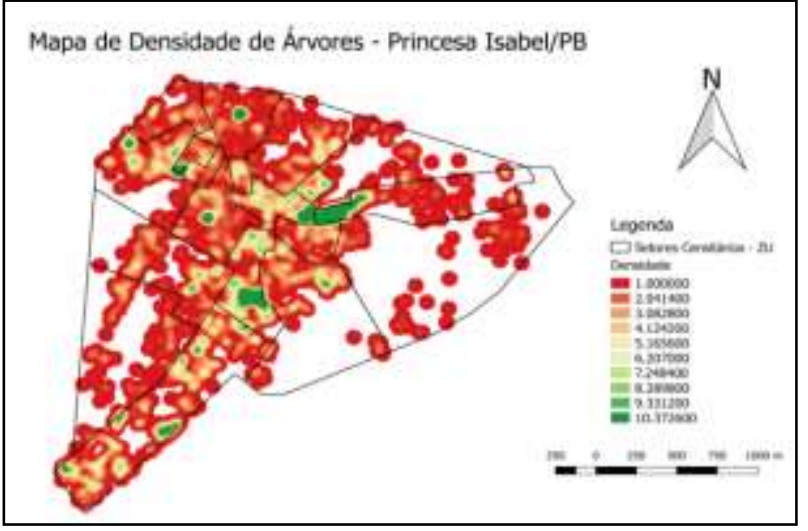

Fonte: autor

Como é possível observar na Figura 1, foi analisado os domicílios particulares permanentes do tipo casa com banheiro de uso exclusivo dos moradores ou sanitário e esgotamento sanitário via rede geral de esgoto ou pluvial, aonde se possui mais de $75 \%$ de domicílios sem esgotamento adequado. Na Figura 2, temos domicílios particulares permanentes do tipo casa com banheiro de uso exclusivo dos moradores, variando entre 0 a 441 domicílios que possuem banheiros exclusivos para os moradores e os que não possuem. Já na Figura 3 se tem os domicílios particulares permanentes do tipo casa com banheiro de uso exclusivo dos moradores ou sanitários e esgotamento sanitário via fossa rudimentar, variam de 0 a 196.

Diante dos mapas gerados percebesse que são poucos domicílios que possuem fossa rudimentar, que são as fossas precárias que prejudicam o meio ambiente, mas ainda não se tem um saneamento para descarte do esgotamento que seja adequado.

$\mathrm{Na}$ figura 4, foi observado as ruas que não possuíam pavimentação e se percebe-se que mais de $50 \%$ das ruas não possuem, o que torna propícias as inundações, aos esgotamentos a céu aberto e o difícil acesso em andar por as ruas as pessoas com necessidades especiais.

A Figura 5 demostra através do mapa uma imagem de satélite, que foi feita a vetorização manual das arvores visíveis e a partir dela criado o mapa de calor utilizando um raio de 100 metros, com o mapa se percebe que a cidade possui pouca arborização o que pode influenciar na temperatura

Em comparação ao que Mascaró (2002, p.13) relatou em alguns dos seus textos, percebeu-se que a cidade demonstrava no âmbito da pesquisa carência em alguns elementos da estrutura urbana. As árvores, em termos de aspectos paisagísticos, proporcionam embelezamento, direcionamento, identidade e delimitação de espaços. Em termos ambientais, as árvores urbanas contribuem para a redução da erosão; para o controle do clima e economia de energia com o sombreamento, a redução da temperatura, a retenção da água no solo, o 
aumento da umidade relativa do ar e a canalização ou obstrução dos ventos; e para o controle da poluição com a amenização de ruídos e da poluição atmosférica.

\section{Conclusões}

As ferramentas do geoprocessamento contribuíram para o trabalho, pois com o auxílio da ferramenta conseguiu-se avaliar os dados do censo de 2010, transformando em mapas temáticos. Esse tipo de estudo pode contribuir para a construção de um futuro plano diretor da cidade, fornecendo informações demostradas no mapa da própria cidade.

Com os dados obtidos, perceber-se que a cidade não se planejou para proporcionar a população uma infraestrutura que possibilite usufruir do meio ambiente e das estruturas físicas, tais elas como: pavimentação adequada, praças para recreação, arborização lhes oferecendo um ar menos poluído e o saneamento básico; de forma a oferecer melhores condições de vida.

\section{Referências}

ABNT - ASSOCIAÇÃO BRASILEIRA DE NORMAS TÉCNICAS, NBR-7207 - Terminologia e classificação de Pavimentação. Rio de Janeiro, 1982.

ARAÚJO A.B. AMARO, V. e VITAL, H. Elaboração de mapas de vulnerabilidade ambiental na região de grossos e tibau do norte, porção setentrional do litoral do $\mathrm{rn}$, a partir de produtos multitemporais de sensoriamento remoto. Anais XI SBSR, Belo Horizonte, Brasil, 05 - 10 abril 2003, INPE, p. 1479 - 1484.

BRASIL. Lei $n^{\circ} .6 .938$ de 31 de agosto de 1981. Dispõe sobre a Política Nacional do Meio Ambiente, seus fins e mecanismos de formulação e aplicação, e dá outras providências. Diário Oficial da República Federativa do Brasil, Brasília, DF, 2 de setembro de 1981. Disponível em: http://www.planalto.gov.br/ccivil_03/leis/L6938.htm . Acesso em: 18.10.2018

LOBATO, C. R.; ANGELIS. B.L. D de. Áreas verdes públicas urbanas: conceitos, usos e funções. Revista Ambiência. Paraná, v.1 n.1 p. 125-139 jan./jun. 2005.

Ministério do Meio Ambiente/2002 - Especificações e Normas Técnicas para a Elaboração de Cartas de Vulnerabilidade Ambiental para Derramamentos de Óleo.

\section{http://www.suapesquisa.com/o_que_e/saneamento_basico.htm}

SANTOS, M. R. R.S; Ranieri, V, E, L. Critérios Para Análise Do Zoneamento Ambiental Como Instrumento De Planejamento E Ordenamento TERRITORIAL. Ambiente \& Sociedade n São Paulo v. XVI, n. 4 n p. 43-62 n out.-dez. 2013 
SEDDON, D.S. N. Vulnerabilidade social no Espírito Santo: conceito e mensuração. Dissertação (Mestrado em Economia) - Universidade Federal do Espírito Santo, Centro de Ciências Jurídicas e Econômicas. 104 f. : il. Espirito Santo. 2014

SOUZA, C. S. O Papel Do Zoneamento Ambiental No Planejamento Municipal. PIDCC, Ano II, Edição no 04/2013, p.154 a 175. Aracaju, Out/2013.

RIBEIRO, Flávia Alice Borges Soares Ribeiro. Arborização urbana em Uberlândia: percepção da população. Revista da Católica, v. 1, n. 1, p. 224-237, Uberlândia, 2009. Disponível em <http://catolicaonline.com.br/revistadacatolica2/artigosv1n1/20_Arborizacao_urbana.pdf >.Acesso em 14 de mar. de 2017. 